\title{
Oxidation of Benzoin to Benzil using Lanthanum Oxide
}

\author{
Govindaraj Usha, Ramesh Prakash, Narayanan Selvapalam, Karuppasamy Karpagalakshmi, \\ Lakshminarayanan Piramuthu
}

\begin{abstract}
Industrially useful class of intermediate such as benzil can be obtained by the oxidation of benzoin, which has been explored extensively. Until now, lanthanum oxide has been not explored for the oxidation of benzoin. Here we report the oxidation of benzoin by the rare earth oxide, lanthanum oxide, which converted quantitatively the oxidized product, benzil,. The product was characterized by FTIR and NMR
\end{abstract}

Keywords: Oxidation, Benzoin, Benzil, Lanthaum oxide.

\section{INTRODUCTION}

$\mathrm{P}$ harmaceutical industry rely on the 1,2-Diketones for the synthesis of medicinally active compounds. The most viable method of preparation of 1,2-diketone is the $\mathrm{SeO}_{2}$ oxidation of monoketones having a free methylene group at the $\alpha$-position, which will be oxidized to ketone efficiently [1]. However, $\mathrm{SeO} 2$ is the most toxic element, which can lead to many medical complications, even in the trace amount present in the drugs. The alternative synthesis of diketone, especially aromatic diketone could be through the intermolecular coupling reaction of benzaldehyde and its derivatives to generate the $\alpha$-hydroxy aromatic ketone [2]. A simple example such compound is benzoin. Benzoin has been synthesized from benzaldehyde and the reaction was catalyzed by metal cyanides, thiamine and many others.[3], [4], [5]. Thus, the conversion of bezoin to bezil becomes important, because, benzoin often over oxidized or rearranged to other unexpected product [6], [7]. Besides, stability of benzil is unimportant for the quantitative conversion of the oxidation of benzoin to benzil. Besides, 1,2-diketones are the starting materials for the synthesis of glycoluril and its functionalized glycolurils have been extensively used for the synthesis of cucurbiturils and its

Revised Manuscript Received on December 15, 2019.

* Correspondence Author

Govindaraj Usha, Center for Supramolecular Chemistry, IRC and Department of Chemistry, Kalasalingam Academy of Research and Education, Krishnankoil 626126, India. n.selvapalam@klu.ac.in

Ramesh Prakash, Center for Supramolecular Chemistry, IRC and Department of Chemistry, Kalasalingam Academy of Research and Education, Krishnankoil 626126, India.n.selvapalam@klu.ac.in

Narayanan Selvapalam*, Center for Supramolecular Chemistry, IRC and Department of Chemistry, Kalasalingam Academy of Research and Education, Krishnankoil 626126, India.n.selvapalam@klu.ac.in

Dr. Lakshminarayanan Piramuthu, Center for Supramolecular Chemistry, IRC and Department of Chemistry, Kalasalingam Academy of Research and Education, Krishnankoil 626126, India.

Karpagalakshmi karuppasamy, Center for Supramolecular Chemistry, IRC and Department of Chemistry, Kalasalingam Academy of Research and Education, Krishnankoil 626126, India. derivatives. Nakamura et.al [8] have utilized benzil for the synthesis of diphenyl cucurbiturils and subsequently functionalized benzils have been used for the synthesis of diamino-diphenyl cucurbituril derivatives [9]. Therefore, a facile synthetic methodology for synthesis of benzil and its derivatives will be very useful for the Pharma industry and for the research purposes.

Benzoin can be oxidized to benzil by several agents. There are merits and demerits on these reagents. It can be categorized based on the source of oxygen supply to the benzoin. For example, Inorganic nitrates and metal oxides are the excellent sources for the supply of oxygen to the starting materials. Some of the representative nitrates are hallium nitrate [10], ammonium nitrate-copper acetate [11], bismuth nitrate-copper acetate[12], and ferric nitrate [13]. Many of transition metal oxidation agents are excellent oxidation reagents. Among them, a few representative examples are ferric oxide-aluminum oxide [14], $\mathrm{VOCl}_{3}$ [15], chromium trioxide on Kieselguhr [16], silica-supported $\mathrm{MnO}_{2}$ [17], ammonium chloro chromate, adsorbed on alumina [18] or silica [19], alumina or silica gel [20] and commercial alumina [21]. Besides, metal nitrates and oxides, there have been reagents such as ( $\mathrm{Mn}$ (III) (pydx-en) $\mathrm{Cl}\left(\mathrm{H}_{2} \mathrm{O}\right)$ )- $\mathrm{Y}$ in combination with $\mathrm{H}_{2} \mathrm{O}_{2}$ also used for this organic transformation [22]. Benzoin can be oxidized by electrochemically by the addition of $\mathrm{KI}$ as an electrolyte to the basic media; which indicates that molecular oxygen can also be used for such oxidation. Despite of all these methods existing for the simple oxidative conversion of secondary alcohol to ketone, there is potential possibility of over oxidation or cleavage of benzoin to the starting materials such as benzaldehyde and benzoic acid. On the other hand, the reaction required highly basic condition, which led to many unwanted rearranged products. Other drawbacks of this reaction include the usage of corrosive acids or toxic metallic reagents, which produced many undesirable products. Therefore, a facile and convenient reagent for the conversion of benzoin to benzil is high desirable for benefit of the pharmaceutical industries and for the synthesis of new cucurbituril derivatives. In this paper, we report an easy and convenient method for the efficient and selective oxidation of benzoin to benzil under reflux conditions in basic media using lanthanum oxide as a oxidizing agent (Scheme 1)

\section{EXPERIMENTAL SECTION}

Chemicals and solvents were purchased from Aldrich, USA; Avra Synthesis Private Ltd, Otto Chemie Pvt Ltd. Fourier Transform Infrared Spectrophotometer were recorded as $\mathrm{KBr}$ pellets on a Shimadzu IR Tracer-100 IR Tracer 100. 


\section{Oxidation of Benzoin to Benzil using Lanthanum Oxide}

${ }^{1} \mathrm{H}$ NMR spectra were recorded at $400 \mathrm{MHz}$ spectrometer using $\mathrm{CDCl}_{3}$ as the solvent and tetramethylsilane as the internal standard. Thin layer chromatography (TLC) was performed On precoated TLC-aluminium foil (silica gel 60) silica plates.

\section{Synthesis of Benzil from benzoin}

Oxidation of Benzoin was performed using lanthanum oxide as a oxidizing agent as given below. In a $50 \mathrm{~mL}$ round bottom flask, $500 \mathrm{mg}$ of benzoin ( $2.3 \mathrm{mmol}$ ) as taken and $30 \mathrm{~mL}$ of ethanol and $700 \mathrm{mg}$ of $\mathrm{La}_{2} \mathrm{O}_{3}$ were added and to it $2 \mathrm{~mL}$ of $\mathrm{NaOH}$ solution $(1 \mathrm{M})$ was added. The reaction mixture was stirred and refluxed for 4 hrs. The completion of the reaction was monitored by TLC (petroleum:ethyl acetate). The yellowish reaction mixture was filtered, and washed the solid product using excess ethanol and the filtrate was evaporated to obtain yellow solid, which was recrystallized in hot ethanol to obtain pure benzil compound (yellow crystals). The product was confirmed by the FTIR and NMR. Benzil: ${ }^{1} \mathrm{HNMR}\left(\mathrm{CDCl}_{3}, 400 \mathrm{MHz}\right) \delta$ (ppm): 7.54 (d, 4H, J = 7.6 Hz), $7.65(\mathrm{t}, 2 \mathrm{H}, \mathrm{J}=7.6 \mathrm{~Hz}), 7.99(\mathrm{t}, 4 \mathrm{H}, \mathrm{J}=7.6 \mathrm{~Hz}) \mathrm{IR}(\mathrm{KBr}) \mathrm{Cm}^{-1}$ $1650(\mathrm{C}=\mathrm{O}, \mathrm{s}), 1446,1591(\mathrm{C}=\mathrm{C}, \mathrm{m}), 719(\mathrm{CH}, \mathrm{m})$.

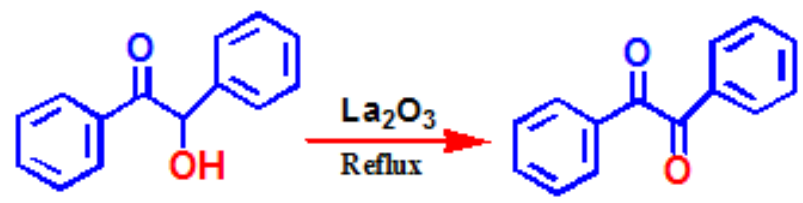

Scheme 1. Conversion of Benzoin to Benzil

\section{RESULTS AND DISCUSSION}

Synthesis of benzil was attracted to us, because we were interested to prepare various substituted diketone for the synthesis of functionalized cucurbiturils and anticipated that such functionalized cucurbituril could be explored in targeted drug delivery purposes. Our initial attempt to synthesis the benzil compounds using $\mathrm{SeO}_{2}$ gave poor yields and unable to isolate the product in pure form. Furthermore, selenium metal deposition in the reaction flask caused serious problems. Our next attempt to use hydrogen peroxide as an oxygen source also failed to give good yield with benzil. Thus, our next attempt was on the lanthanum oxide, which has not been explored for the purpose of oxidation of secondary alcohol as well as for the conversion of benzoin to benzil. We heated the benzoin with lanthanum oxide for a long duration, which showed no indication of product, despite of treatment of benzoin subjected to microwave irradiation and long duration of heating the reaction mixture. All our other attempts such as stirring long duration at room temperature and addition of organic acid and mineral acid also did not render the expected product. When we examined the literature, we noticed that many of the reactions have been carried out under basic conditions. Thus, we added $2 \mathrm{~mL}$ of $1 \mathrm{M} \mathrm{NaOH}$ solution to the reaction mixture containing lanthanum oxide and benzoin, which immediately turned the solution to yellow and that indicated the hope of getting the expected product. Upon optimizing the condition, we obtained the best results. Briefly, $500 \mathrm{mg}$ of benzoin was treated with $700 \mathrm{mg}$ of lanthanum oxide in ethanol solvent and to that $2 \mathrm{~mL}$ of $1 \mathrm{M}$ $\mathrm{NaOH}$ waa added and heated the reaction mixture for $4 \mathrm{hrs}$.
TLC was monitored, which indicated the formation of the product, as the product was verified by the authentic sample. As shown in Fig.1, the TLC indicates that benzoin was quantitatively converted to benzil and the product could be recrystallized by ethanol. The product was further confirmed by the $1 \mathrm{H} \mathrm{NMR}$ as represented in fig. 1 . The significant peaks of symmetrical benzene peaks of benzil appeared at 7.54, 7.65 and 7.99 confirmed the product formation.



Fig. 1. TLC and NMR spectrum of Benzil

As shown in fig.1, the significant peaks of benzoin hydroxyl group at 4.6 and the adjacent hydrogen at $5.95 \mathrm{ppm}$ disappeared. Furthermore, multiple peaks at 7.2 - 7.4 slowly changed to the symmetrical peaks at 7.54 and that indicates the conversion of benzoin to benzil. This was further confirmed from the FTIR obtained for the benzil as shown in fig.2. The significant peaks of 1660, 1594 and 1579 indicates the presence of $\mathrm{C}=\mathrm{O}$, arene $\mathrm{C}=\mathrm{C}$ and the absence of hydroxyl peaks indicates the conversion of benzoin to benzil (fig. 2)

We have proposed the following mechanism for the conversion of benzoin to benzil (Fig. 3). The first step in the conversion of benzoin to benzil could be the dehydrogenation of secondary alcohol by the based sodium hydroxide, and subsequently upon heating with $\mathrm{La}_{2} \mathrm{O}_{3}$ the sodium cation could be replaced by the lanthanum and the oxide of lanthanum could provide the source for oxygen for the oxidation, which rendered the final product of benzil. As mentioned above, lanthanum oxide alone could not able to

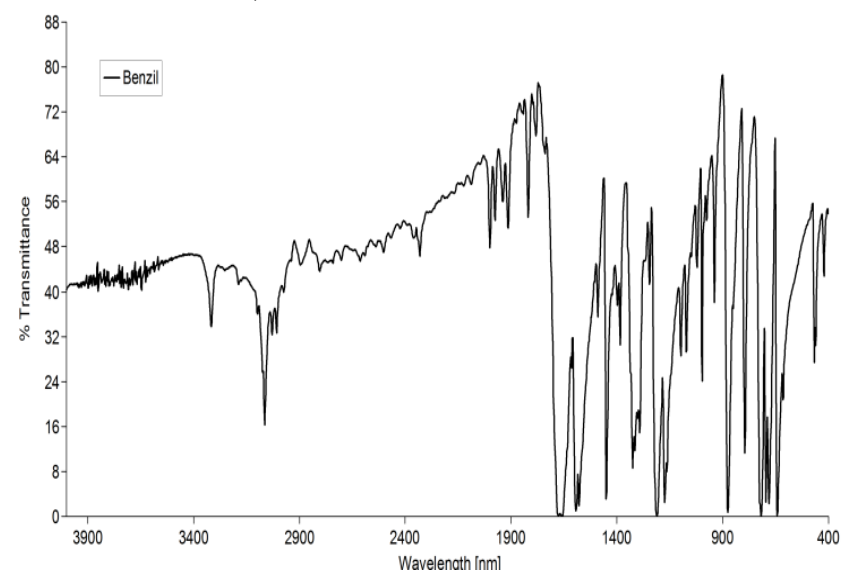

Figure 2. FTIR of Benzil 
perform the oxidation of benzoin. Therefore we anticipated the participation of base in the mechanism.<smiles>C[13C](O)C(=O)C(O)Br</smiles><smiles>O=C(Br)C([18O])[18O][Na]</smiles><smiles>CC[Te]C(=O)C(=O)Br</smiles>

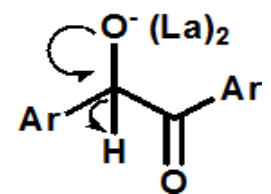

Figure 3: Proposed mechanism for the conversion of benzoin to benzil

\section{CONCLUSION}

For the first time benzion oxidation has been demonstrated using lanthanum oxide in combination with sodium hydroxide and the product, benzil was recrytallized by ethanol. The reaction was performed in ethanol solvent under basic condition. No conversion was observed in neutral condition and by excluding the base, sodium hydroxide. Overall, the present method provides a facile conversion of benzoin to benzil with ease of isolation and purification.

\section{ACKNOWLEDGMENT}

This work is financially supported by DST- SERB, India under Early Career Research Award (ECR/2015/000318). R. $\mathrm{P}$ and $\mathrm{K}$. $\mathrm{K}$ thanks to KARE for offering University $\mathrm{PhD}$ fellowship. G. U. thanks to the SERB for offering Project Assistant fellowship.

\section{REFERENCES}

1. E. J. Corey, J. P. Schaefer, "Studies on the Mechanism of Oxidation of Ketones by Selenium Dioxide Part I" J. Am. Chem. Soc., vol. 82, February 1960, pp. 917-929.

2. M. Mousavi, H. Seyfi, "Preparation of $\alpha$-Hydroxy Ketones from Aromatic Aldehydes” Org. Chem. J., vol. 1, September 2011, pp. 17-23,

3. Y. He, Y. Xue, "Mechanism insight the Cyanide- catalyzed Benzoin condensation: A Density functional theory study" J. Phys. Chem, vol. 114, July 2010, pp. 9222-9230.

4. S. Bag, V. V. Vaze, and M. S. Degani "Microwave Assisted Benzoin Condensation using Thiamine as Catalyst" J. Chem. Res., vol. 4, April 2006, pp. 267-269.

5. R. S. Menon, A. K. Biju, and V. Nair "Recent advances in N-heterocyclic carbene (NHC)-catalysed benzoin reactions" Beilstein J. Org. Chem., vol. 12, March 2016, pp. 444-461.

6. H. Wynberg, H. J. Kooreman, "The mechanism of the Hinsberg thiophene ring synthesis" J. Am. Chem. Soc., vol. 87, pp. 1739-1742, April 1965.

7. W. W. Paudler, J. M. Barton, "The synthesis of 1,2,4- triazine" J. Org. Chem., Vol. 31, June 1966, pp. 1720-1722.

8. H. Isobe, S. Sato, E. Nakamura "Synthesis of disubstituted cucurbituril[6]uril and its rotaxane derivative" J. Am. Chem. Soc., vol. 48, pp. March 2002,1287-1289.

9. H. Cong, X. Longni, X. Xiao, Y. Huang, Z. Tao and G. Wei “ Synthesis and separation of cucurbit[n]urils and their derivatives" Org. Biomol. Chem., vol. 14, March 2016, pp. 4335-4364.

10. M. Weiss, M. J . Appel, "The catalytic oxidation of benzoin to benzil" J. Am. Chem. Soc., Vol. 70, November 1948, pp. 3666-3667.

11. S. A. Tymono, B. A. Nattier, and R. S. Mohan "Oxidation of benzoins to benzil using bismuth(III)nitrate-copper(II)acetate" Tetrahedron Lett., Vol. 40, October 1999, pp. 7657-7659.

12. A. M. Paul, A. C. Khandekar, and M. A. Shenoy, "Silica supported ferric nitrate nonahydrate:selective oxidation of benzoin under mild conditions" Synth. Commun., vol. 33, August 2006, pp. 2581-2584.

13. Y. Sun, N. Ueyama, and A. Nakamura, "Air oxidation of p-sunstituted benzoin to the corresponding benzil by Fe(II)-cysteine peptide complex" Tetrahedron, vol. 48, February 1992, pp. 1557-1566.

14. C. Zhebin, S. Zhengui, "Study on catalytic oxidation of benzion by molecular oxygen in presence of ferric oxide supported on activated aluminum oxide" Chin. J. Org. Chem., Vol. 22, June 2002, pp. 446-447,

15. M. Kirihara, Y. Ochiai, and S. Takizawa,"Aerobic oxidation of $\alpha$-hydroxycarbonyls catalysed by tricholorooxyvanadium:effient synthesis of $\alpha$-dicarbonyl compounds" Chem. Commun., September 1999, pp, 1387-1388,

16. J. D. Lou, C. Zhang, and G. Q. Wang, “ Oxidation of benzions to benzyls with chromium trioxide supported on kieselghur under viscous condtions" Synthetic React Inorg Metal Org Nanometal Chem., vol. 39, January 2009, pp. 6-8.

17. A. M. Khandekar, B. M. Paul, "Silica supported mamganese dioxide:an efficient reagent for oxidation of benzions" Synth. Commun., vol. 32, January 2002, pp. 2931-2935.

18. G. S. Zhang, Z. Shi, M. F. Chen, and K. Cai, "Ammonium Chlorochromate Adsorbed on Alumina: A New Reagent for the Oxidation of Alcohols and Benzoins to the Corresponding Carbonyl Compounds" Synth. Commun., vol. 27, August 1997, pp. 953-956.

19. G. S. Zhang, Z. Shi, M. F. Chen, and K. Cai, "Preparation of Alumina-supported Dimethylammonium chlorochromate (DMCC) and its use in the oxidation of alcohols and benzoins" Synth. Commun., vol. 27, July 1977, pp. 215-218.

20. N. Noroozi-pesyn, A. H. Dabbagh, "Alumina and silica oxides as catalyst for the oxidant of benzoins to benzil under solvent free conditions" Molecules, vol. 10, November 2005, pp. 1364-1368.

21. K. Skobridis, V. Thedorou, and E. Weber, "A very simple and chemoselective air oxidation of benzions to benzyls by use of alumina" ARKIVOC, vol. 13, March 2006, pp. 102-106.

22. S. I. M. Paris, Ü. A. Laskay, S. Liang et al., "Manganese(II) complexes of di-2-pyridinylmethylene-1,2-diimine di-Schiff base ligands: structures and reactivity," Inorganica Chimica Acta, vol. 363, October 2010, pp. 3390-3398.

\section{AUTHORS PROFILE}

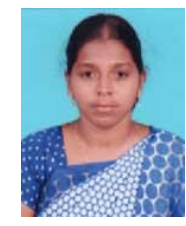

Govindaraj Usha, was born in Tirunelveli, Tamilnadu in 1991. She received her M.Phil degree from the Bharathiar university, Coimbatore, in 2015 and obtained her M. Sc. degree in 2013 at karunya University, Coimbatore. She has started her Ph. D. studies in 2016 under the supervision of Dr. N. Selvapalam at kalasalingam Academy of Research and Education, Krishnankoil, India. Her research interests are in the area of organic synthesis and supramolecular chemistry



Ramesh Prakash, born in Karur,Tamilnadu in 1991 He received his M.Phil degree from the BharathidasanUniversity, Trichy, in 2015 and obtained his MSc degree in 2014 at St. Joseph's College, Trichy. He joined Ph.D. in 2015 under the supervision of Dr. N. Selvapalam at Kalasalingam Academy of Research and Education inVirudhunagar district. He is awarded a direct-Senior Research Fellowship from CSIR in 2018 to till date. His research interest is on the area of nanomaterials synthesis and supramolecular chemistry.

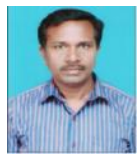

Dr. Narayanan Selvapalam, received his M.S.and Ph.D degrees from Mysore University and IIT Delhi, respectively. $\mathrm{He}$ is presently working as Associate Professor at the Kalasalingam Academy of Research and Education (Kalasalingam University) His research interests include supramolecular chemistry, glycoluril based polymers, Chemistry of cucurbiturils and cyclodextrins, organic synthesis and sensors. 
Oxidation of Benzoin to Benzil using Lanthanum Oxide

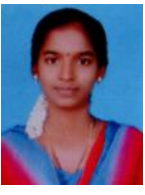

Karpagalakshmi karuppasamy, was born in sivakasi, Tamilnadu in 1993. She received her M.. Sc. degree from the Madurai Kamaraj University, Madurai, in 2016 and obtained her B. Sc degree in 2014 from, Madurai Kamaraj University, Madurai. She has started her Ph. D. studies in 2016 under the supervision of Dr. N. Selvapalam at kalasalingam academy of Research and Education, Krishnankoil, India. Her research interests are in the area of organic synthesis, nano-materials and supramolecular chemistry

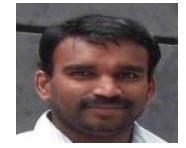

Dr. Lakshminarayanan Piramuthu was born in Kizhapuliyur, Tenkasi, India, in 1979. He studied Chemistry at Sri Paramakalyani College, Alwarkurichi, India. He obtained his Ph.D. degree in the area of Development of Receptors for Recognition of Halides and Water Clusters: Further Functionalization of Receptors with Fluorophoric Units from Indian Association for the Cultivation of Science IACS, Kolkata under the direction of Professor Pradyut Ghosh. His basic focus is, to study the biologically relevant anion recognition and sensing of the synthetic receptors, he has also contributed to other areas such as crystal engineering and organic synthesis. 